\title{
The Enterprise Human Resources Management Based On Knowledge Management and Collaboration
}

\author{
Ying Cai* \\ Economics and management school Wuhan University Hubei. China \\ Yingcai@163.com
}

\begin{abstract}
The enterprise should break the situation that the technological collaboration and market collaboration are separated from each other, which should set up the technological collaboration and market collaboration management from the angle of total collaboration management; it is a very urgent issue under the challenge of the current environmental changes. In this paper, it takes the concept and definition of technological collaboration management as the starting point, with the aid of the interpretation of the related content of technological collaboration and enterprise technological collaboration management, combined with the theoretical model of technological collaboration, discussing and exploring the enterprise technological collaboration as well as the choice of market collaboration strategies.
\end{abstract}

Keywords: Technological collaboration; Market collaboration; Collaboration management

\section{Introduction}

Science and technology can play more and more important role in the social and economic development, in today's market economy environment, the competition between enterprises finally is in the competition of core technology; enterprise can guarantee itself not to be eliminated by the market only by having constant technological collaboration, the only way that enterprises can maintain long-term competitive advantage is the continuous and effective management of technological collaboration, which can strengthen their own core technology capabilities. Technological collaboration management has become the most important catalyst for the success of the enterprise to obtain the market competition. Under the challenge of technological changes, technological collaboration management began to enter into the eyes of Chinese entrepreneurs in 1998 [1]. In 2000, the management of technological collaboration has become the new exploration direction for Chinese enterprises, which can also be called as "The Year of Technological collaboration Management". Technological collaboration management as a new management mode is sweeping the country along with the wave of technological change, as well as the construction of information [2].

\section{The Concept of Technological collaboration Management}

Technological collaboration management is the evolution of technological management theory. With the continuous development of technological management theory, technological management has a new position [3]. Researchers are having more and more awareness about the technological management, which should be incorporated into the enterprise strategic management activities, the focus of management should be placed in the technological collaboration management, only the organic combination of the two aspects can play a strategic role in technological management, therefore, it can strengthen the core competitiveness of enterprises. [4] Thus, we can see that technological collaboration management actually should include two aspects, namely, technological collaboration and enterprise technology management. It is a kind of enterprise technological management method based on technological collaboration. The management of technological collaboration should be always for the rational allocation of resources, the operation of the system should be more efficient, so as to improve production capacity, according to the enterprise strategic planning, which can be regarded as the management activities to guide the management of enterprise. 


\section{Technological collaboration}

The core of technological collaboration management is technological collaboration. Technological collaboration means the collaboration of producing technology, including the development of new technology, as well as the application of the existing technology and re-collaboration [5]. (see Figure 1) Technological collaboration is a complicated process. It begins with the collaboration awareness and collaboration concept, through the constantly discovery, so as to solve problems with the ultimate goal of making a new projects put into practice, so as to have economic value and social value. Specifically speaking, it mainly includes new product development, new production methods, new organization and management form, new supply channel and new market development and so on. The collaboration of producing technology, which begins with the basic research, the practical application of the production, the success of the business, serving the business, whose process is quite complex [6]. At present, most scholars believe that the process of technological collaboration can be divided into several different stages, such as research and development, pilot, mass production, technology promotion and popularization (see Fig.1).

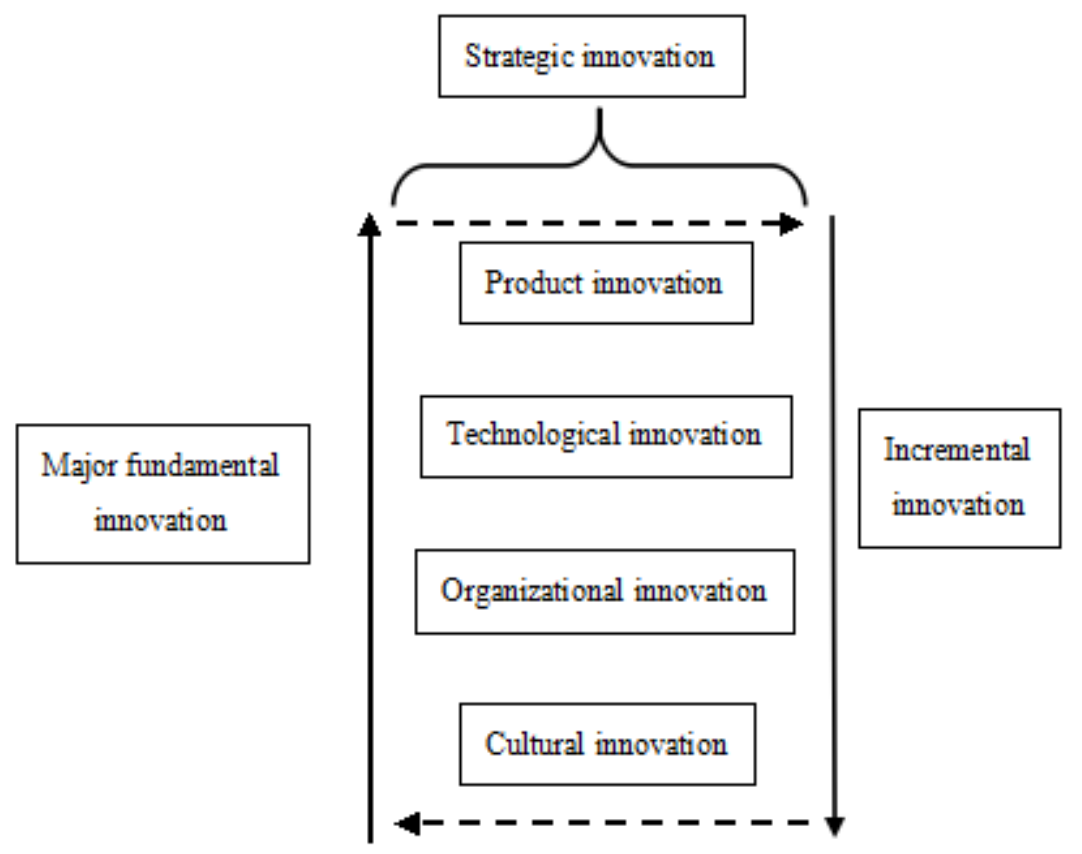

Fig. 1 The Operating Mechanism of Enterprise Collaborative collaboration

\section{Enterprise Technology Management}

The essence of technological collaboration management is the management of technology. Technology management is a subsystem of the entire enterprise management system, which mainly refers to the development of enterprise technology, product development, technical cooperation, technology transformation and technology transfer, planning, organization, command, coordination and control as well as a series of management activities in general [7]. The purpose of enterprise technology management is according to the nature of the work of science and technology to adopt the scientific work flow, with plans, step by step, so as to use reasonable and legitimate enterprise technical force and resources, which will be the latest scientific and technological achievements that can be quickly transformed into realistic productivity and realize the technical progress of enterprises and economic benefits with double harvest (see Fig. 2). 


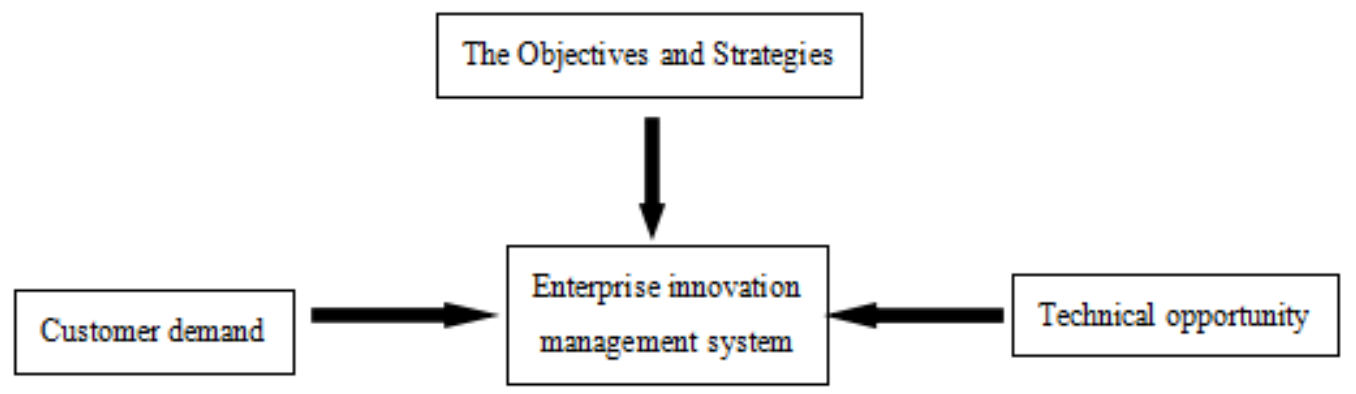

Enterprise internal and external environment

Fig.2 Concepts Model of TI Management System

The basic process of technological collaboration management can be summed up as follows: enterprise timely making corresponding adjustment according to the changes of the external environment; making rapid assessment on information changes, making the strategic planning; making new innovative projects according to the strategic plan, making the relevant schedule table; during the process of making the advanced technological collaboration management, making correcting errors timely, so as to ensure the activities can be carried on smoothly.

\section{The Connotation of Enterprise Technological collaboration Risk}

Technological collaboration is a kind of risk behavior, the enterprise's technological collaboration behavior has the feature of symmetry with the survival risk, on one hand, the enterprise may get huge profits brought the technological collaboration, on the other hand, it may bear the corresponding risks. Researchers defined technology collaboration risk as follows: due to the uncertainty of the external environment, the difficulty and complexity of the technological collaboration of the projects, as well as the limited innovator's own ability and capability, which leads to the failure of technological collaboration, suspended, revoked or not up to the target probability and consequences (see Fig. 3). And the enterprise technology collaboration is driven by the enterprise under the market mechanism, in order to obtain high returns or core competitiveness, the enterprises will take the initiative to carry out technological collaboration behavior. Moreover, the enterprise technology collaboration risk is not limited to the technological collaboration project, which is caused by the enterprise technical collaboration projects and then it can spread to the entire enterprise. Therefore, the risk of technological collaboration can be defined as the risk because of the failure of enterprise technological collaboration projects, as well as the sum of the other chain risks that may be caused.

Technological Innovation Risk Benefits

\begin{tabular}{|c|c|c|c|c|c|c|c|}
\hline 8000 & & & & & & \\
\hline 7500 & & & & & & & \\
\hline 7000 & & & & & & & \\
\hline 6500 & & & & & & & \\
\hline 6000 & & & & & & & \\
\hline & 1 & 2 & 3 & 4 & 5 & 6 & 7 \\
\hline
\end{tabular}

Time(Year)

Independent Innovation Benefits

Fig.3.The Chart of Technological collaboration Risk Benefits 


\section{Conclusion}

From the perspective of the above factors of the collaborative collaboration, the successful development of collaborative collaboration needs the integrated support from the enterprise collaborative collaboration management framework. At the same time, whether the collaborative collaboration process can be a success or failure lies in whether it can adapt itself to the changes of environment and resource or not. Therefore, the architecture of collaborative collaboration management can provide support for the collaborative collaboration process mainly by introducing external variable characteristics, so as to establish external adaptability of architecture and support the collaborative collaboration process.

\section{References}

[1]. Gerwin D. 1988. Strategic and Organizational Implications of Computerized Manufacturing Technology. 5th Edition, Higher-Education press

[2]. Glaser B G,Strauss A L. 1965. Temporal aspects of dying as a non-scheduled status passage. American Journal of Sociology. vol.71, pp13-15

[3]. Devaus, d. a. 2001. Research design in social research. CA: Sage Publications.

[4]. Edwin, Mansfield. 1988. Industrial collaboration in Japan and the United States, Science. vol.24, pp49-61

[5]. Eisenhardt K M. 1989. Building theories from case study research. Academy of Management Review. vol.14, pp535-550

[6]. Taylor Hazel, Artman Edward, Woelfer Jill PalzkilL 2012. Information technology project risk management; bridging the gap between research and practice. Journal of Information Technology. vol.27, pp17-34

[7]. Graham Andrea M., Rogers Jamie. 2011. Technology collaboration risk mitigation and organizational strategy: A balanced framework for technology managers. PICMET: Portland International Center for Management of Engineering and Technology, Proceedings, IEEE Computer Society. pp1-6. 